\title{
PROFILE OF AUTHORS
}

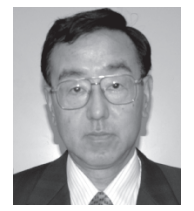

Name: Yoshimi Asagai M.D.

\section{Current:}

2005-: Chairman of the Board, Shinano Handicapped Children's Hospital

2003-: Professor (temporary) of Orthopedic surgery Tokyo Medical University

1986-: Director of Shinano Handicapped Children's Hospital Specialized societies:

- The president and Life Member of 1st International Phototherapy Association (IPTA)

- The president of 18th Japan Laser Therapy Association (JALTA)

\section{Education:}

1992: Obtained degree as Doctor of Medical Science

1976: Graduated from Tokyo Medical University

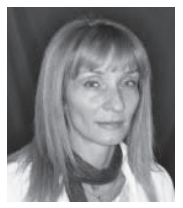

Name: Galia Grigorova Zhegova, DMD, PhD Current:

Assistant- Professor in the Department of Pediatric dentistry, Faculty of dental medicine, Medical University, Sofia, Bulgaria.

Guest-lecturer at EMDOLA (European Master Degree in Oral Laser Application) of the University of Nice Sophie Antipolis (France) and University of Parma (Italy).

Lecturer at the Centre of Laser Dentistry of the Faculty of Dental Medicine-Sofia.

Dental private practice in her clinic in Sofia, Bulgaria.

\section{Education:}

2014: PhD in Pediatric Dentistry, Faculty of dental medicine Medical University, Sofia Bulgaria;

1996: Postgraduate diploma in Pediatric Dentistry, Faculty of dental medicine - Medical University, Sofia Bulgaria.

2001: Postgraduate diploma in General Dentistry, Faculty of dental medicine - Medical University, Sofia Bulgaria.

\section{Membership:}

Bulgarian Scientific Dental Association; Bulgarian Dental Association (BDA); Association of the Pediatric Dentists in Bulgaria.

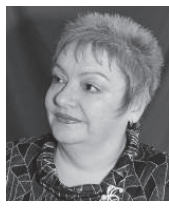

Name: Maya Rasheva Rashkova, PhD

Current:

Professor of pediatric dentistry, Vice Dean of Faculty of dental medicine - Medical University, Sofia, Bulgaria

\section{Education}

2006: PhD of pediatric dentistry, Faculty of dental medicine Medical University, Sofia Bulgaria;

1987: Specialization in periodontology in Budapest Medical University, Hungary;

1984: Postgraduate diploma in Pediatric Dentistry, Faculty of dental medicine - Medical University, Sofia Bulgaria.

\section{Membership:}

Bulgarian Scientific Dental Association; Bulgarian Dental Association (BDA); Association of the Pediatric Dentists in Bulgaria; Member of the Faculty Board of the Dental Medicine Faculty in Sofia medical University; Member of the Accreditation Committee and Post Graduate Education of the BDA Independent Expert at the National Agency for Valuation and Accreditation.

\section{Editorial Board:}

Problems of dental medicine - scientific journal of Faculty of dental medicine - Medical University, Sofia

\section{Scientific researches and publications:}

136 scientific articles; contribution to 10 monographies and textbooks of pediatric dentistry; leading author in 8 scientific projects;

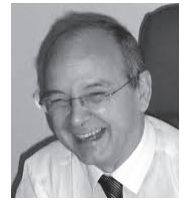

Name: Jean-Paul ROCCA

Current:

1991-: Professor, University of Nice Sophia Antipolis.

2002-: Vice Dean, in charge of Research (University of Nice), President of Scientific Committee (Nice Dental Faculty).

Dental practitioner (Laser Unit), Director of Clinical Research.

\section{Education:}

1985: PhD in Human Biology (Microbiology)

1978: PhD in Dental Sciences

\section{Scientific Activities:}

Director of "Laser Technology and Oral Environment" research laboratory (TELEO) of the University of Nice.

Director of EMDOLA (European Master Degree in Oral Laser Applications) of the University of Nice.

Co-Editor of International Magazine of Laser Dentistry.

Past President of the World Federation for Laser in Dentistry (WFLD).

Honorary President of EMDOLA ACADEMY

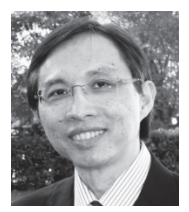

Name: Dr. Ambrose Chan BDS Hon (Uni.Syd); G Dip Clin Dent (Uni. Syd); MScDent (Uni. Syd); FRACDS

\section{Current:}

Honorary Research Affiliate, BMI, Uni Sydney.

Representative of Australian Dental Association in the Standards Australia Committee on Laser.

Chairman, World Federation for Laser Dentistry-Asia Pacific Division.

Peer-reviewer for the Journal Lasers in Medical Science and LaserTherapy.

Radiation Safety Officer certified by the Queensland health.

Chairman, board of studies on laser certification -WFLD-Asia Pacific Division.

\section{Work Experience:}

incorporates lasers in dental practice over 30 years; Granted by ALD: Educatorship (2000), Mastership (2008) and Standard Laser Course Provider (2000-2011)

\section{Specialized Societies:}

Chairman of the organizing committee in laser conferences, which include the 2010 International Laser Dentistry Symposium, 2012 World Association for Laser Therapy Congress (dental stream), and the 2013 World Federation for Laser Dentistry-Asian Pacific Symposium.

Awards:

The winner of "Best Oral Scientific Presentation Award"-2010 WFLD Congress. 


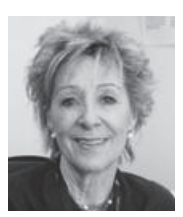

\section{Name: Patricia Armati}

\section{Current:}

Founder, Co-Director and Vice President of the Nerve Research Foundation

Member of the Advisory Committee of the Institute of Neuromuscular Research, Westmead Children's Hospital

Editorial Boards of the Journal of Neurolipids and the International Scholarly Research Network (ISRN) - Neurology.

Work experience:

2005-2009 Board member of the Internation Peripheral Nerve Society

- 2011 Member the Editorial Board of the Journal of the Peripheral Nervous System

Reserch interests:

Neuroscience, particularly neuroglial cells, developmental neuroscience, tissue culture models and genetic analysis relat ed particularly to Multiple Sclerosis, Alzheimers disease and peripheral neuropathies. Also interested in the neural mechanisms underlying low level laser therapy for neuropathic pain

Name: Ghanbari Habiboallah, DDS, MSc.

\section{Current:}

Associated Professor, Department of Periodontics School of Dentistry and Dental Research Center, Mashhad University of Medical Sciences, Mashhad, Iran.

Academic Vice chancellor, Faculty of Dentistry, Mashhad University of Medical Sciences, Mashhad, Iran

Education:

1993: MSc. Graduate Department of Periodontics School of Dentistry and Dental Research Center, Mashhad University of Medical Sciences, Mashhad, Iran.

1993: First rank of Iranian Board Certification in Periodontics, Iran.

\section{Membership:}

Director, Postgraduate Studies in Periodontics, Mashhad Dental School, Mashhad University of Medical Sciences, Iran.

Member, National (Iranian) Board of Examiners for Periodontal Specialty.

Member, Iranian Association of Periodontology.

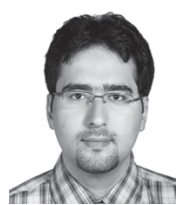

Name: Zakeri Mahdi, DDS

Current:

Surgeon-Dentist, Department of Periodontics School of Dentistry and Dental Research Center, Mashhad University of Medical Sciences, Mashhad, Iran.

Education:

2008: DDS, School of Dentistry and Dental Research Center, Mashhad University of Medical Sciences, Mashhad, Iran.

2007: "Presidential Recognition Award", Top National Student of the year (Major: Dentistry, Program: doctorate,).

2008: "British invention of the year award", British inventors society, London.

2009: "DIPLOM Award", Russian House for International Scientific and Technological Cooperation.

\section{Membership:}

2009- Member of Iranian inventors association

2008- Member of Special Talent Guide Committee, Ministry of Health and Education, Tehran, Iran.

2005-2006 Member of Central Council of Research Committee, Mashhad University of Medical Sciences, Mashhad Iran.

Member of Iranian Dental Association
Name: Naderi Nasab Mahbobeh

\section{Current:}

Associated Professor, Department of Medical Bacteriology \& Virology, Emam Reza Hospital, Faculty of Medicine, Mashhad University of Medical Sciences, Mashhad, Iran.

\section{Education:}

PhD, Department of Medical Bacteriology \& Virology, Faculty of Medicine, Mashhad University of Medical Sciences, Mashhad, Iran.

\section{Membership:}

Member, Iranian Association of Medical Bacteriology \& Virology.

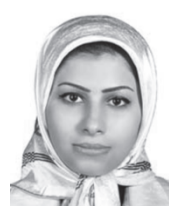

Name: Zareian Jahromi Mina

Current:

Surgeon-Dentist

Education:

2009: DDS, School of Dentistry, Shahed University, Tehran, Iran

2008: "Presidential Recognition Award", Top National Student of the year (Major: Dentistry, Program: doctorate,).

2008: "British invention of the year award", British inventors society, London

\section{Membership:}

Member of Iranian inventors association, 2009-Now.

Member of Special Talent Guide Committee, Ministry of Health and Education, Tehran, Iran, 2008-Now.

Member of Iranian Dental Association

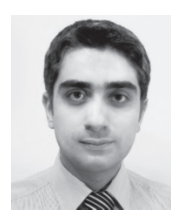

Name: Faghihi Sina

Current:

Surgeon-Dentist

Education:

2008: DDS, School of Dentistry and Dental

Research Center, Mashhad University of Medical Sciences, Mashhad, Iran.

\section{Membership:}

Member of Iranian Dental Association

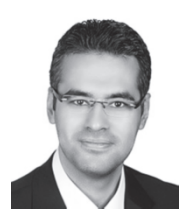

Name: Zakeri Majid

Current:

Surgeon-Dentist

Education:

2011: DDS, School of Dentistry and Dental

Research Center, Mashhad University of Medical Sciences, Mashhad, Iran.

2014: Fellowship in Aesthetic Dentistry from "Universita degli Studi di Genova"

"DIPLOM Award", Russian House for International Scientific and Technological Cooperation, 2009

\section{Membership:}

Member of Iranian Dental Association

Member of Iranian inventors association.

Name: Takashi Nakamura, MD

\section{Current:}

Associate professor, Department of Orthopedic Surgery Toho University Hospital

\section{Education:}

1992 : Graduated from Toho University School of Medicine Specialized Societics:

Knee joint surgery 


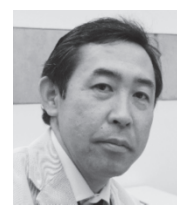

Name: Satoru Ebihara, MD

Current:

Professor and Chairman of Department of Rehabilitation Medicine Toho University Graduate School of Medicine, Tokyo, Japan Education:

1990: Graduated from Tohoku University, Sendai Japan Specialized Societics:

Board Member of Japanese Geriatric Society

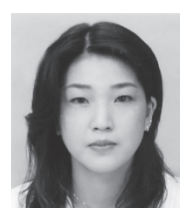

Name: Ikuko Ohkuni, M.D

Current:

Lecturer of Dept of Rehabilitation Medicine, Toho University

Education:

of Medicine

1997: Graduated from Toho University School

\section{Specialized Societies:}

Board Member of Japanese Society Rehabilitation Medicine

Name: Hideaki Izukura, MD

\section{Current:}

Department of rehabilitation Medicine, Toho University Hospital

Education:

1995: Graduated from Toho University School of Medicine

Specialty:

Neuro surgery and Rehabilitation Medicine

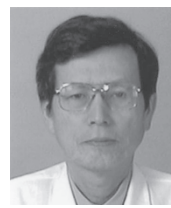

Name: Takashi Harada, M.D.

\section{Current:}

Visiting Professor of Dept of Rehabilitation

Medicine, Toho University

Education:

1969: Graduated from Toho University School of Medicine

Specialized Societies:

Board Member of Japanese Society Rehabilitation Medicine

Board Member of Japan Laser Therapy Association

President of Japan Laser Therapy Association (1999)

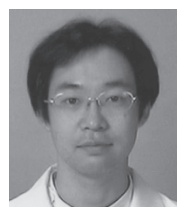

Name: Nobuyuki Ushigome, M.D.

\section{Current:}

Senior Chief Rsident of Dept of Rehabilitation

Medicine, Toho University

Education:

of Medicine

Specialized Societies:

Board Member of Japanese Society Rehabilitation Medicine

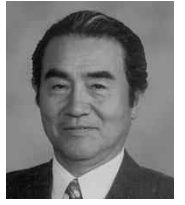

Name: Toshio Ohshiro, M.D. PhD

\section{Current:}

- Board Member of International Society for Laser Surgery and Medicine

- Vice president and Board Member of Japan Society for Laser Surgery and Medicine

- Honorary President of World Association for Laser Therapy

- Founding and Chief editor of "Laser Therapy"

- Visiting professor, Department of Plastic and Reconstructive

Surgery, School of Medicine, Keio University

- Director of Japan Medical Laser Laboratory

- Director of Ohshiro Clinic

Specialized Societies:

- President of the First Meeting of the International Laser Therapy Association

\section{Education:}

1974: Department of Dermatology, Cincinnati University, studied under Prof. Leon Goldman

1965: Department of Plastic and Reconstructive Surgery, School of medicine, Keio University.

\section{Number of the Books:}

93 (English 25, Japanese 63) "The ROLE of the LASER in DERMATOLOGY An Atlas" "LASER TREATMENT FOR NAEVI" (Recent work)

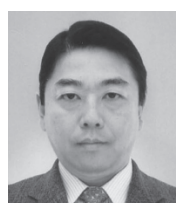

Name: Yoshiro Musha, M.D.

Current:

Assist Professor of Dept of Orthopaedic Surgery, Toho University Ohhashi Hospital

Education:

of Medicine

1984: Graduated from Toho University School

Specialized Societies:

Board Member of Japanese Society of Orthopaedic Surgery

Board Member of Japan Laser Therapy Association

Board Member of Japanese Society of Spinal Surgery

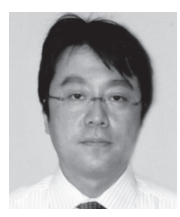

Name: Hiroshi Takahashi,MD

Current:

Professor Dept of Orthopaedic Surgery Toho University

Education:

of Medicine

1988: Graduated from Toho University School

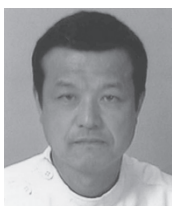

Name: Kazuaki Tsuchiya, MD

Current:

Professor Dept of Orthopaedic Surgery Toho

University

\section{Education:}

of Medicine

1980: Graduated from Toho University School

Specialized Societics:

Board Member of Japanese Society of Orthopaedic Surgery

Board Member of Japan Society of Orthopaedic Oncology 
Name: Ayako Kubota, MD

\section{Current:}

Associate professor, Department of Orthopedic Surgery Toho University Hospital

\section{Education:}

1997: Graduated from Toho University School of Medicine Specialized Societics:

Knee joint surgery

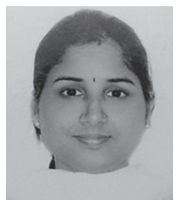

Name: Dr. Ambika Sharma, MDS

(Periodontology)

Ex-Senior Resident, AIIMS, New Delhi

Education:

2004, Bachelor Of Dental Surgery (BDS ) DAV

Dental college, Yamunanagar, India

2011, Masters of Dental Surgery (MDS) in Periodontology Government Dental college, Ahmedabad, India

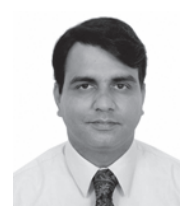

Name: Vijay Prakash Mathur

Current:

Member Secretary- Institute Ethics Sub Committee for Monitoring of AE in Clinica Trials

Additional Professor, Pedodontics and Preventive Dentistry Centre for Dental Education and Research, WHO Collaborating Centre for Oral Health Promotion National Centre for Excellence for Implementation of National Oral Health Programme, All India Institute of Medical Sciences

\section{Qualification:}

Master in Dental Surgery (Pedodontics and Prev. Dent) Research Interests: Soft Tissue Lasers in Dentistry, Dental Public Health and Policy, Epidemiology, Qualitative Research, Pharmacovigilance

\section{Publications}

Author and contributors for 45 research articles and books in chapters. Contributor to several National Reports and Guidelines, IEC material for oral health awareness, Contributor to SOP's for Ethics Sub committee for AIIMS.

\section{Editorial Board:}

Gerodontology, Acta Odontologica Scandinavica, European Science Editing, Indian Journal of Pediatrics, Indian Journal for Medical Research, Indian Journal of Dental Research, Indian Journal of Community Medicine, Indian Journal of Palliative care, International Journal of Laser Dentistry, Journal of Indian Society of Pedodontics and Preventive Dentistry, Indian Journal of Dermatology, Indian Journal of Public Health

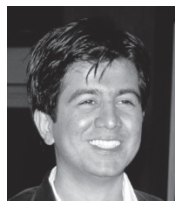

Name: Divesh Sardana

\section{Graduation:}

BDS from Manipal Academy of Higher Education, Karnataka, India

\section{Post-graduation:}

MDS (Pedodontics and Preventive Dentistry) from Post-graduate Institute of Medical Education \& Research, Chandigarh, India

\section{Current position:}

Senior Resident, Department of Pedodontics and Preventive Dentistry

Centre for Dental Education and Research

WHO Collaborating Centre for Oral Health Promotion

National Centre of Excellence for Implementation of National Oral Health Programme

All India Institute of Medical Sciences

Member:

Indian Dental Association, Indian Society of Pedodontics and Preventive Dentistry, Indian Society of Dental Research 